\title{
A AÇÃO PROJETUAL COLETIVA E PARTICIPATIVA NO PROJETO DE REDESENHO DO PÁTIO INTERNO DO BLOCO DISCENTE-I FCT-UNESP - CAMPUS PRESIDENTE PRUDENTE
}

Yanne Nigro Torres, Evandro Fiorin

Universidade Estadual Paulista - FCT/UNESP. Curso de Arquitetura e Urbanismo, Presidente Prudente - SP. E-mail: yanne.nigro@hotmail.com

\section{RESUMO}

Neste artigo buscamos apresentar uma experiência realizada na extensão universitária junto ao NAU - Núcleo de Projetos Arquitetônicos e Urbanos da FCT - Faculdade de Ciências e Tecnologia da UNESP - Campus de Presidente Prudente-SP. Aqui discutimos a elaboração do projeto de redesenho do pátio interno de um dos Blocos de Salas de Aulas e Laboratórios da FCT-UNESP, onde o trabalho coletivo e participativo na ação projetual dos discentes envolvidos foi a tônica da proposta. Assim, explicitamos aqui a metodologia para o desenvolvimento projetual adotado, os resultados obtidos, bem como os ganhos e as perdas diante do trabalho coletivo e participativo ora realizado.

Palavras Chave: Projeto, Arquitetura, Extensão Universitária, Redesenho, UNESP.

\section{THE COLLECTIVE AND THE PARTICIPATORY ACTION IN THE REDESIGN OF INNER COURTYARD OF THE BLOCO DISCENTE-I FCT-UNESP - CAMPUS PRESIDENTE PRUDENTE}

\begin{abstract}
In this paper, we seek to present an experiment conducted in extension by the NAU - Nucleus for Architectural and Urban Projects of FCT - Faculty of Sciences and Technology of UNESP - Campus of Presidente Prudente-SP. Here we discuss the elaboration of the project of redesign of the internal courtyard of the Blocks of Classrooms and Laboratories of FCT-UNESP, where the collective and participatory work in projetual action of the students involved was the focus of the proposal. Thus, we explain here the methodology for the development projetual adopted, the results obtained, as well as gains and losses on the collective and participatory work done.
\end{abstract}

Key Words: Project, Architecture, University Extension, Redesign, UNESP. 
O projeto de redesenho do pátio interno de um dos Blocos de Salas de Aulas e Laboratórios da UNESP - Universidade Estadual Paulista "Júlio de Mesquita Filho" - Campus Presidente Prudente foi solicitado ao NAU - Núcleo de Projetos Arquitetônicos e Urbanos ${ }^{1}$ da FCT - Faculdade de Ciências e Tecnologia da UNESP pela direção da unidade, no sentido de melhorar a qualidade dos espaços e a ocupação humana do "miolo" do edifício recentemente reformado ${ }^{2}$. Este prédio é bastante importante para a história da faculdade, pois foi um dos primeiros a serem construídos e recebeu, no início da década de 1970, no auge da ditadura militar, um grande mural de 3,60 por 1,60 metros em sua entrada principal (que se abre para o pátio), pintado pelo artista plástico Cirton Genaro, também, a pouco tempo restaurado ${ }^{3}$.

Nesse sentido, por esses motivos, o projeto do redesenho do pátio interno deste edifício se fazia necessário para complementar e guarnecer as obras já instauradas no local, além de também colaborar para ganhos espaciais para os frequentadores do lugar, já que abriga algumas salas de aula (o Ateliê de Projetos que se abre para o pátio) e diversos laboratórios da instituição, bem como o próprio espaço do NAU. Desta forma, os alunos bolsistas e voluntários do NAU envolvidos nessa ação projetual tinham para si uma experiência única: redesenhar o seu espaço de convívio da universidade.

Diante dessa oportunidade, para o desenvolvimento desse redesenho levamos em conta a ideia de pesquisa-ação (THIOLLENT, 1986, p. 16) tendo em vista que o trabalho de projeto em si deveria ser coletivo e participativo. Dessa forma buscamos integrar vários discentes representantes de diversos anos do Curso de Arquitetura e Urbanismo da UNESP, do centro acadêmico e da empresa júnior, além de permitir a participação e opinião dos funcionários, docentes e outros discentes da instituição. Com esse intuito a proposta objetivou um desenho que

\footnotetext{
${ }^{1}$ O NAU colabora para consolidar o curso de Arquitetura e Urbanismo reforçando sua inserção social e comunitária, uma vez que sua produção se orienta para a realização de projetos voltados a instituições municipais, estaduais, entidades civis e religiosas, autarquias, fundações, organizações sem fins lucrativos, comunidades e prefeituras municipais da região do Oeste Paulista, com a finalidade de aprimorar a qualidade de vida da população. Com seu viés extensionista, o aluno da graduação tem a possibilidade de exercitar a futura profissão em um espaço que permite aos docentes e discentes, bolsistas e voluntários serem, sobretudo, parceiros no desenvolvimento de pesquisas e da concepção projetual. Deste modo, busca desmistificar a aprendizagem de projeto de arquitetura e urbanismo, diante da dicotomia existente entre: o que ensina e o que aprende; pois estimula e tem como pressuposto uma maior troca de experiências. O aluno da graduação que participa de quaisquer das atividades projetuais do NAU deixa de ser um mero aprendiz para se tornar um agente importante, pois adquire responsabilidades. Cf. FIORIN, E. (org.). Espaços projetados a partir da extensão: as experiências do núcleo de projetos arquitetônicos e urbanos - Unesp /Presidente Prudente. São Paulo, Cultura Acadêmica, 2014, p. 13.

${ }^{2}$ O edifício do antigo Colégio de Aplicação foi construído na década de 1960 defronte à Estação Meteorológica (a primeira construção efetiva do Campus da UNESP de Presidente Prudente, ao lado do atual Campo de Futebol), no terreno que fora o DEMA Departamento Estadual de Mecanização Agrícola. Nesse pavilhão, se acomodou todo o embrião do que seria a Faculdade de Ciências e Tecnologia, anos mais tarde. Cf. ALEGRE, M. Faculdade de Ciências e Tecnologia Ontem... Faculdade de Ciências e Tecnologia Hoje. Uma trajetória de 47 anos (subsídios para uma história oral). Presidente Prudente, FCT, 2006, p. 23.

${ }^{3}$ O painel "Breve História do Homem" foi um presente do autor e uma homenagem à Faculdade de Filosofia, Ciências e Letras de Presidente Prudente, onde este realizou seu curso de Ciências Sociais. "Em depoimento, entregue por escrito, o artista afirma que o desejo, na época da realização do painel, era o da expressão de sentimentos e ideias, num contexto de repressão política e de patrulhamento. O painel seria iluminado de forma a parecer escultórico, um friso, um marco quase monumental, que atestasse a reflexão crítica que existia na instituição, em tempos contrários a tais iniciativas intelectuais." Cf. VERMEERSCH, P. Artista plástico restaura mural em Presidente Prudente. Disponível em: Portal FCT-UNESP.

<http://www.unesp.br/portal\#!/noticia/13146/artista-plastico-restaura-mural-em-presidente-prudente/>. (Acesso: 12 de agosto de 2014).
} 
tinha como intenção possibilitar uma maior apropriação do espaço por todos os usuários, e que não fosse apenas um espaço "trancafiado" de contemplação. Logo preconizava-se poder atravessar de um lado ao outro pelo "miolo" da edificação, além da permanência no referido pátio. A busca por novos materiais, ecológicos, baratos e de fácil acesso, também foi uma das necessidades que se propôs alcançar.

\section{METODOLOGIA}

Inicialmente identificamos a área, uma vez que o Bloco de Aulas e Laboratórios Discente-I, da FCT-UNESP passara por uma reforma em meados do primeiro semestre de 2014 e não haviam sido realizadas melhorias no seu pátio interno. Assim, um grupo de alunos se organizou a partir do $\mathrm{NAU}^{4}$ para que reuniões de trabalho fossem realizadas, de modo que não houvesse somente discentes de um único ano do Curso de Arquitetura e Urbanismo e que, também, várias entidades pudessem estar presentes na empreitada. Membros do NAU (Núcleo de Projetos Arquitetônicos e Urbanos), do Centro Acadêmico (CACAU), da Empresa Júnior (Ópera Krios) formaram, então, a equipe responsável pelo levantamento da área em questão e pela elaboração do projeto de redesenho do pátio interno do Bloco Discente I preconizando uma experiência de ação projetual coletiva e participativa. Com a formação do grupo de estudantes, em contato com a Diretoria de Serviços da FCT-UNESP ${ }^{5}$, além da participação de um professor orientador ${ }^{6}$ foram espontaneamente recebidas as ideias dos usuários do Bloco de Aulas e Laboratórios do Discente-I. Neste caso, obtivemos uma quantidade expressiva de opiniões a serem levadas em conta na elaboração da referida proposta, diante da necessidade de redesenho do pátio interno, sempre de forma a propiciar a utilização do público, contando com dispositivos que favorecessem a permanência no espaço e que a solução encontrada fosse ecológica, barata e de fácil acesso, a fim de que pudesse ser exequível, mas principalmente, tendo em vista soluções experimentais (ROSA; WEILAND, 2013). Por esse motivo, o método empírico foi bastante utilizado, mas não prescindiu de uma verificação de sua validade diante das referências paisagísticas já consolidadas. Sendo assim foram realizados levantamentos e pesquisas necessárias à elaboração da proposta em questão, atendendo às necessidades dos usuários que poderiam utilizar o espaço: professores, funcionários, estudantes e visitantes.

\footnotetext{
${ }^{4} \mathrm{O}$ grupo foi formado pelos bolsistas do Núcleo de Projetos Arquitetônicos e Urbanos (NAU): Luccas Pinheiro Pereira, Maurício Katie Abe e Yanne Nigro Torres; Membros do Centro Acadêmico (CACAU): André Abreu de Rezende, Luana C. Carvalho de Oliveira e Marina Mendonça Ferreira; Membro da Empresa Júnior (Ópera Krios): Patrícia Missae Takaki.

${ }^{5}$ A Diretoria de Serviços da FCT-UNESP é o órgão responsável pelo planejamento, coordenação, supervisão e orientação das diversas atividades que se praticam dentro do espaço físico da FCT-UNESP de Presidente Prudente.

${ }^{6}$ Prof. Evandro Fiorin, coordenador do NAU e do Curso de Arquitetura e Urbanismo da FCT-UNESP (2014-2016).
} 
RESULTADOS

A proposta projetual partiu da análise do Bloco Discente-I, onde foram detectados os acessos para a edificação e posterior ingresso ao seu pátio interno. Três entradas para o Bloco de Aulas e Laboratórios advêm do espaço externo e a quarta faz comunicação com o edifício da PósGraduação da mesma Instituição.

Antes da reforma pela qual o Discente-I foi submetido havia apenas dois acessos ao pátio interno: um coligado a entrada principal do prédio e outro ligado à Pós Graduação. Assim, na Figura 01 é possível perceber um único trajeto existente no pátio interno proporcionado pelo piso cimentado existente. No entanto, na mesma Figura 01 percebemos duas novas aberturas para o pátio, que foram proporcionadas devido à implantação de portas-balcão no Ateliê de Projetos, o que fez com que o acesso ao "miolo" fosse valorizado. Como demonstra a Figura 02 o pátio é de terra batida e dotado de vegetação esparsa tendo algumas árvores de grande porte, as quais proporcionam áreas ricas em sombreamento.
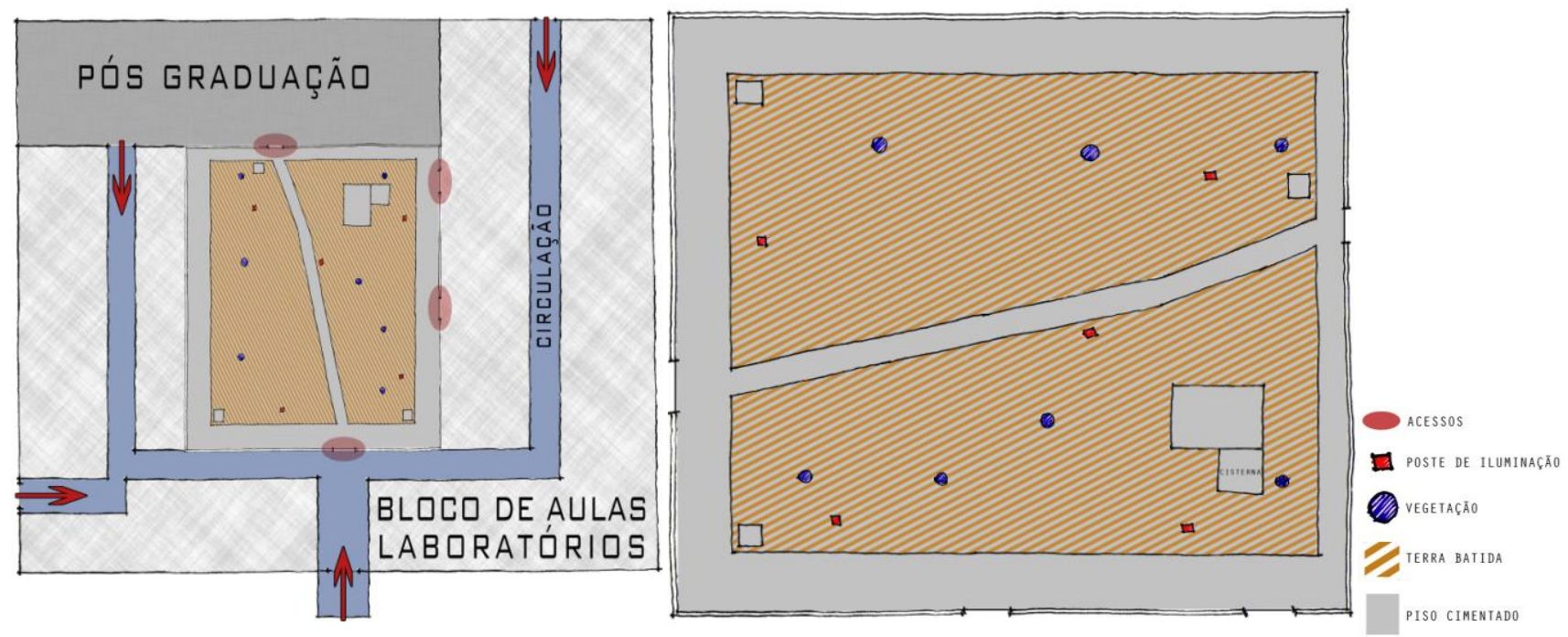

Figuras 1 e 2. Levantamento dos acessos ao Bloco de Aulas e Laboratórios, Discente-I, do Campus da UNESP de Presidente Prudente e dos acessos ao seu pátio interno; Croqui da Planta Baixa do Pátio Interno existente e levantamento. Fonte: Arquivos do NAU, 2014.

O partido para a ação projetual se baseou no percurso possível através dos acessos disponíveis no pátio. $\mathrm{O}$ trajeto existente que corta o espaço ao meio permaneceria, além de novos percursos que seriam implantados, advindos do Ateliê de Projetos. As árvores não seriam removidas, bem como os postes de iluminação permaneceriam nos mesmos locais, com a inserção de outros, em pontos de acordo com o novo desenho. 

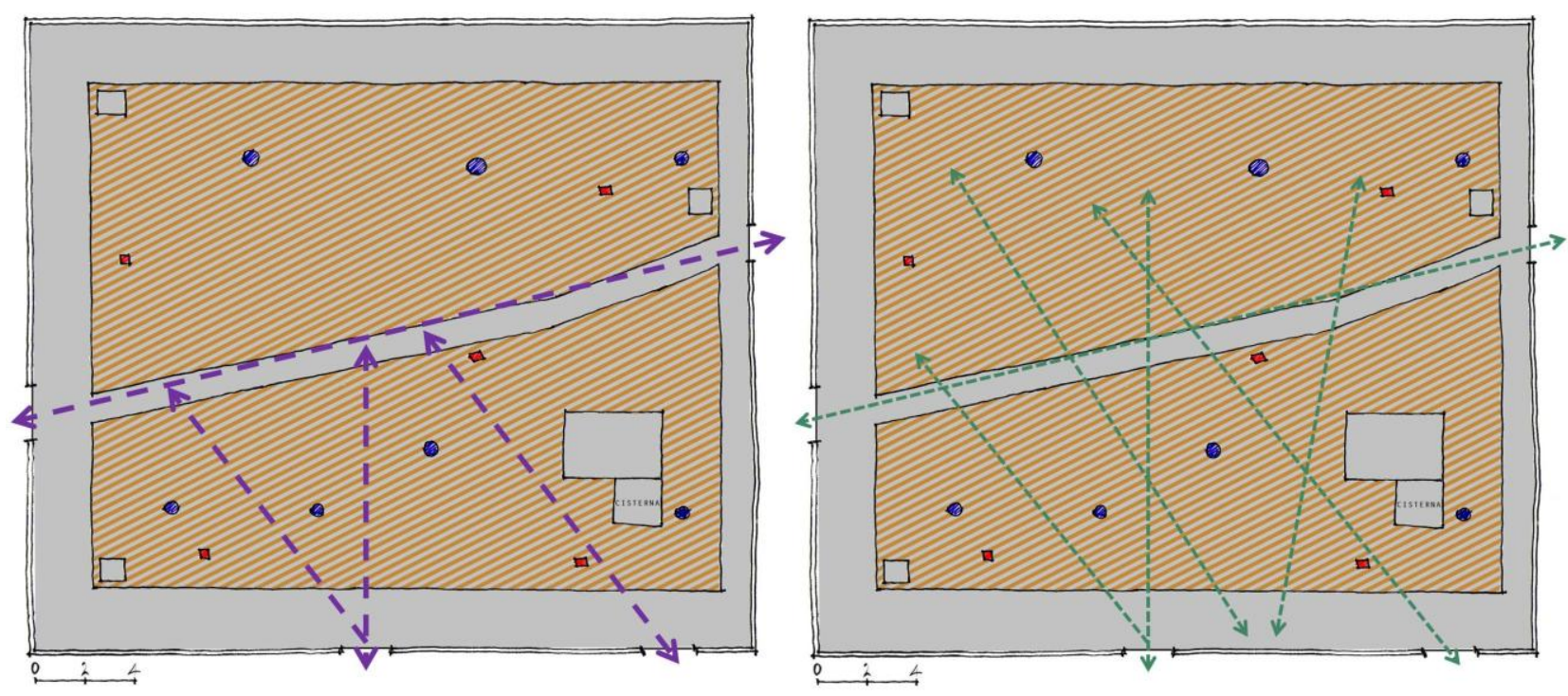

Figuras 3 e 4. Croqui da Planta Baixa do Pátio Interno com traçado existente, evidenciando os trajetos possíveis (em roxo), devido à inserção de novas aberturas; Croqui da Planta Baixa do Pátio Interno com traçado existente, indicando os novos possíveis trajetos (em verde). Fonte: Arquivos do NAU, 2014.

A partir dos novos trajetos possíveis, a intenção do projeto era a de permitir que todo o espaço do pátio interno fosse utilizado, de modo que o redesenho indicasse as possíveis rotas de passagem e permanência dos indivíduos.
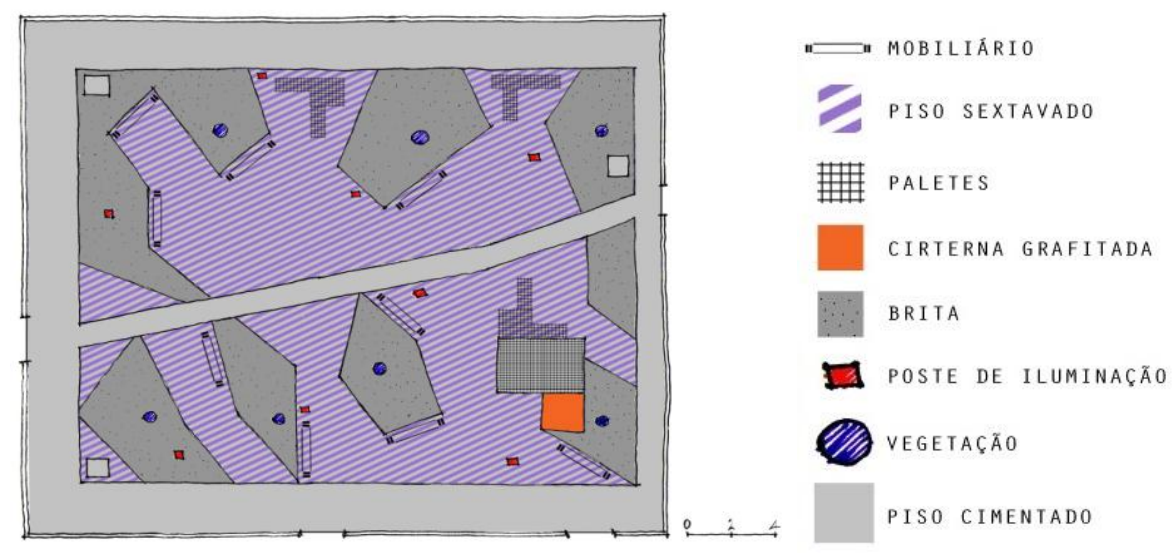

Figura 5. Croqui esquemático do redesenho do Bloco de Salas e Laboratórios do Discente I do Campus de Presidente Prudente da UNESP. Fonte: Arquivos do NAU, 2014.

A pesquisa de materiais levou o grupo de estudantes a optar por formas baratas, rápidas e ecológicas para a constituição do projeto de paisagismo. Nesse sentido, o revestimento da praça seria constituído por blocos de concreto sextavado, devido à abundância do mesmo na FCT-UNESP e da facilidade de acesso e manuseio para os funcionários da Diretoria de Serviços; além de britas que seriam inseridas nas proximidades das árvores pré-existentes. Ambos os materiais proporcionam grande permeabilidade do solo e facilitam a captação da água da chuva. Com o 
redesenho e aumento da área passível de utilização do pátio, novos postes de iluminação foram propostos em pontos estratégicos, visto que o projeto prevê também a permanência de usuários à noite. Além disso, uma pesquisa de formas e materiais foi feita para que o mobiliário fosse executado da maneira mais ecológica e barata possível, com materiais de fácil acesso. Constituído de madeira e bambu, material abundante na FCT-UNESP, o mobiliário seria bastante variável.

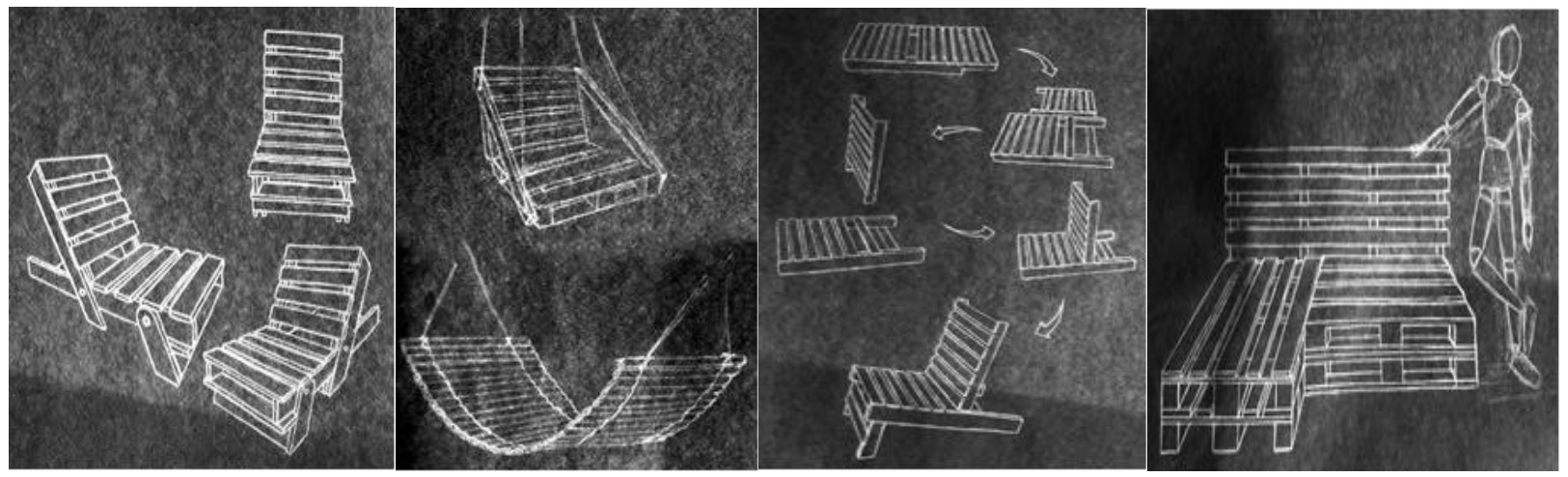

Figuras 6, 7, 8, 9. Croquis dos bancos individuais constituídos por páletes; Croquis esquemáticos dos bancos individuais suspensos por cordas e confeccionados com bambu; Croqui do esquema de montagem para os bancos; Croqui de banco coletivo, com modelo humano. Fonte: Arquivos do NAU, 2014.

O pátio contaria com bancos individuais e coletivos formados por páletes, dispostos de maneira que o usuário faça sua utilização da maneira que melhor the convier, além de bancos suspensos de bambu tipo redes. Por não ser fixo, o mobiliário poderia ser deslocado para outras áreas do pátio, dependendo da necessidade do usuário. O mobiliário "instalação" para o Largo da Batata, em São Paulo foi utilizado como referência para a constituição dos bancos que o grupo de estudantes optou por inserir no pátio interno ${ }^{7}$. Uma cisterna existente no pátio pertencente ao prédio da Pós-Graduação seria utilizada como um mural, a fim de que os próprios estudantes pudessem grafitá-la. Dessa forma, esperava-se que o projeto incitasse o sentido de "pertencimento" ao lugar e a permanência do público, dando liberdade para que todos pudessem se expressar através do grafite, além de favorecer a utilização do espaço como uma praça multiuso, com mobiliário cambiante, dentro de uma edificação restrita da Faculdade de Ciências e Tecnologia da UNESP de Presidente Prudente.

\footnotetext{
${ }^{7}$ COELHO, L. Largo da Batata ganha mobiliário de madeira e novas plantas. Veja em São Paulo. 15 ago. 2014. Disponível em: $<$ http://vejasp.abril.com.br/materia/largo-da-batata-ganha-mobiliario-de-madeira-e-plantas>. (Acesso: 15 set. 2014).
} 

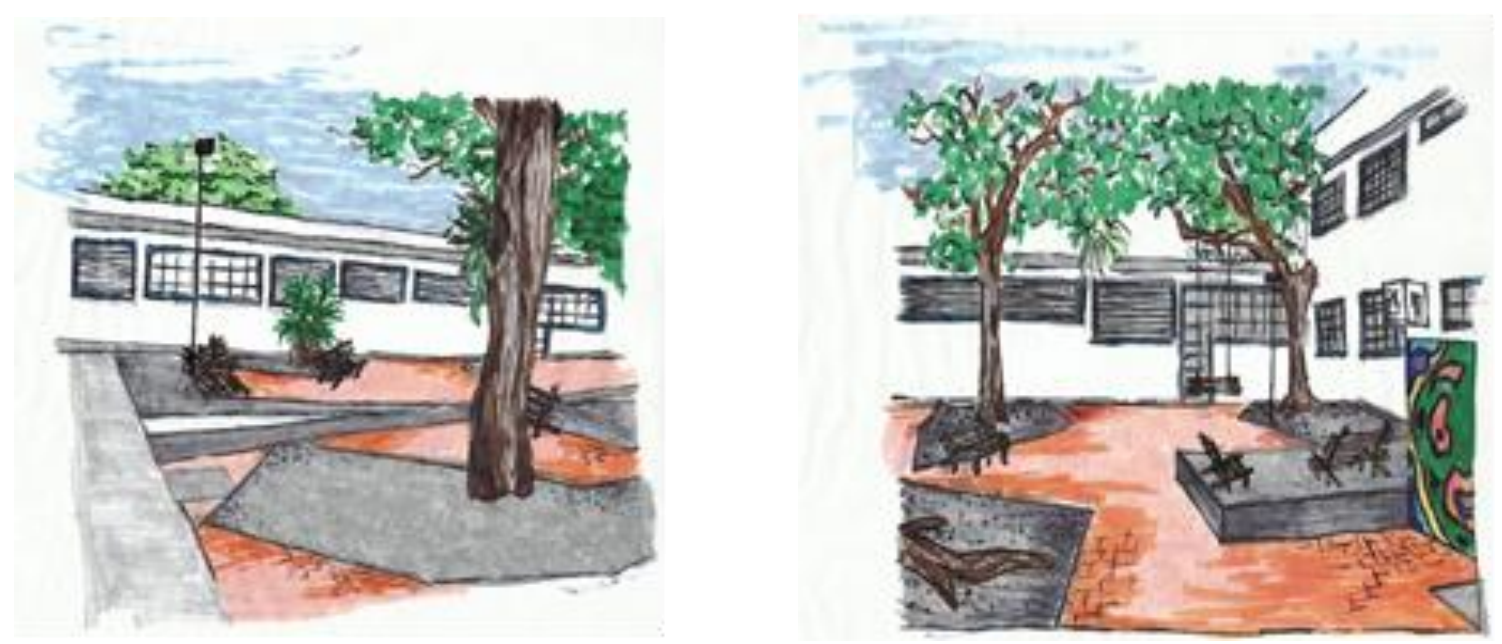

Figuras 10 e 11. Perspectiva de uma das vistas do projeto implantado, com a vegetação existente e mobiliário proposto; Perspectiva de outra vista do Pátio com implantação do redesenho, mobiliário e cisterna grafitada. Fonte: Arquivos do NAU, 2014.

\section{DISCUSSÃO}

A possibilidade de construir um espaço pelos estudantes e para os estudantes sob uma ação projetual coletiva e participativa na universidade é uma oportunidade única para os envolvidos, principalmente porque exercitam o seu ofício em um local que conhecem muito bem: a própria instituição onde estudam. Além disso, a experiência deste trabalho pôde ser uma forma de tentar solucionar as adversidades existentes no local em questão, tendo que levar em conta limitações orçamentárias para o feitio do referido projeto.
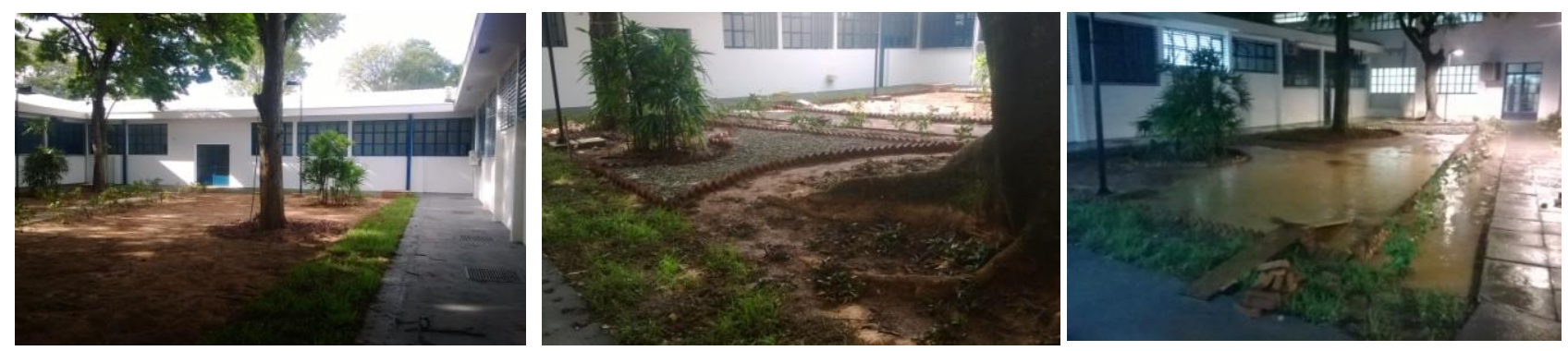

Figuras 12, 13, 14. Pátio Interno do Discente I antes da intervenção feita às pressas; Vista a partir de uma das portas do Ateliê de Projetos evidenciando o ajardinamento feito às pressas pela Diretoria de Serviços da FCT-UNESP; Alagamento resultante da ação da chuva em um ambiente reformulado sem projeto adequado.

Fonte: Arquivos do NAU, 2014.

Talvez por esse fato, o projeto ainda não pôde ser colocado em prática. O que existe hoje no pátio interno é um ajardinamento feito às pressas pela Diretoria de Serviços da FCT-UNESP e sem a elaboração de um projeto específico. As obras se iniciaram sem as precauções adequadas concorrendo para criar um ambiente inóspito e de difícil acesso e apropriação. 


\section{CONSIDERAÇÕES}

A realização de uma ação projetual coletiva e participativa é um desafio que perpassa pela necessidade de permitir a coexistência de diversos pontos de vista, a compreensão das discordâncias pelo diálogo, na busca de consenso (HABERMAS, 1984). Uma tarefa árdua e que precisa ser constantemente exercitada. No caso do projeto de redesenho desse pátio interno tivemos ganhos em relação ao aumento do grau de coleguismo dos alunos envolvidos na proposta projetual, no empenho em tornar as decisões de projeto coletivas e participativas, mas, também, perdas, principalmente no trato com os órgãos gestores da unidade, sobretudo por conta dos curtos prazos a serem cumpridos para o levantamento e dificuldades de orçamento. No entanto, esperamos que a proposta de redesenho aqui apresentada ainda possa sair do papel, de maneira a estabelecer novas táticas de uso e ocupação do referido pátio, de modo a favorecer novas possibilidades de interação e apropriação humanas.

\section{REFERÊNCIAS}

ALEGRE, M. Faculdade de Ciências e Tecnologia Ontem... Faculdade de Ciências e Tecnologia Hoje. Uma trajetória de 47 anos (subsídios para uma história oral). Presidente Prudente: FCT, 2006.

COELHO, L. Largo da Batata ganha mobiliário de madeira e novas plantas. Veja em São Paulo. 15 ago. 2014. Disponível em: <http://vejasp.abril.com.br/materia/largo-da-batata-ganha-mobiliariode-madeira-e-plantas>. (Acesso: 15 set. 2014).

FIORIN, E. (org.). Espaços projetados a partir da extensão: as experiências do núcleo de projetos arquitetônicos e urbanos - Unesp /Presidente Prudente. São Paulo: Cultura Acadêmica, 2014.

HABERMAS, J. Mudança Estrutural da Esfera Pública. Rio de Janeiro: Tempo Brasileiro, 1984.

ROSA, M. L.; WEILAND, U. E. Handmade Urbanism. Mumbai - São Paulo - Istanbul - Mexico City Cape Town. From Community Initiatives to Participatory Models. Berlim: Jovis Verlag, 2013.

THIOLLENT, M. Metodologia da Pesquisa-Ação. São Paulo: Cortez, 2008.

VERMEERSCH, P. Artista plástico restaura mural em Presidente Prudente. Disponível em: Portal FCT-UNESP. <http://www.unesp.br/portal\#!/noticia/13146/artista-plastico-restaura-mural-empresidente-prudente/>. (Acesso: 12 de agosto de 2014). 